\title{
Parasitosis of the vertebral canal mimicking lumbar intervertebral disc herniation: a case report
}

\author{
Marcin Tyrakowski ${ }^{1}$, Magdalena Kwiatkowska ${ }^{2}$, Maria Czubak-Wrzosek ${ }^{1 *}$ (D) and Jarosław Czubak ${ }^{2}$
}

\begin{abstract}
Study design: Case report.

Background: It is a case of dracunculiasis of the spine mimicking lumbar intervertebral disc herniation.

Case presentation: A 57 year-old Caucasian male was admitted to the hospital because of the left $L 5$ radiculopathy lasting for 2 months. The pain in the left lower limb was associated with muscle weakness on dorsal flexion of the foot, paresthesia of the dorsal aspect of the foot and tingling in the big toe. Neurological examination revealed: muscle weakness on dorsal flexion of the foot, impaired light touch and pin prick test on the dorsal aspect of the foot and positive Lasègue's sign. Magnetic resonance imaging (MRI) examination revealed L4L5 intervertebral disc herniation with sequester compressing the left L5 nerve root. The open L4-L5 left side discectomy was performed. During the sequester evacuation 3 pieces of nematodes were removed and preserved in $10 \%$ of formaldehyde solution. After the surgery the patient was pain free with normal neurological examination. The diagnosis of dracunculiasis was based on the morphology of the nematode and on exclusion of the other parasites. DM infestation could not be confirmed with molecular testing that was impaired by the formaldehyde.

Conclusions: Parasite infestation should be considered even in cases with obvious MRI of lumbar intervertebral disc herniation. If a nematode was found accidentally during any surgery it should be preserved in a $0.9 \%$ saline, not in formaldehyde, not to disturb the molecular tests.
\end{abstract}

Keywords: Dracunculiasis, Spinal parasite, Parasitosis of vertebral canal

\section{Background}

Dracunculiasis, also known as guinea worm disease, is caused by a nematode worm, Dracunculus medinensis (DM). Dracunculiasis is transmitted to humans via drinking water containing copepods infected with larvae of DM. After being ingested the copepods release DM larvae that penetrate the host's stomach, intestinal wall, and enter the abdominal cavity or retroperitoneal space where they grow. Mature DM females grow to a length

\footnotetext{
* Correspondence: czubakwrzosek@gmail.com

'Department of Spine Disorders and Orthopedics, Centre of Postgraduate Medical Education in Warsaw, Konarskiego 13, 05-400 Otwock, Poland Full list of author information is available at the end of the article
}

of $100 \mathrm{~cm}$, they penetrate deeply into the connective tissue adjoining long bones or joints and migrate typically within the subcutaneous tissue to the skin, mostly of the lower extremities. About 1 year after the infestation the female worm induces a painful blister formation on the skin. When the blister ruptures, the larvae are released by the adult female worm on contact with water and are subsequently ingested by copepods [1-4].

Unusual locations (besides the skin) of the mature DM in the human body have been described and involve the pancreas, lung, periorbital tissue, testes, pericardium and the spinal cord, radio-ulnar joint or Bartholin gland [2, 5-7].

(c) The Author(s). 2021 Open Access This article is licensed under a Creative Commons Attribution 4.0 International License, which permits use, sharing, adaptation, distribution and reproduction in any medium or format, as long as you give appropriate credit to the original author(s) and the source, provide a link to the Creative Commons licence, and indicate if changes were made. The images or other third party material in this article are included in the article's Creative Commons licence, unless indicated otherwise in a credit line to the material. If material is not included in the article's Creative Commons licence and your intended use is not permitted by statutory regulation or exceeds the permitted use, you will need to obtain permission directly from the copyright holder. To view a copy of this licence, visit http://creativecommons.org/licenses/by/4.0/. The Creative Commons Public Domain Dedication waiver (http://creativecommons.org/publicdomain/zero/1.0/) applies to the data made available in this article, unless otherwise stated in a credit line to the data. 
The aim of this study was to present a case of dracunculiasis of the vertebral canal that was mimicking, both clinically and radiographically, lumbar intervertebral disc herniation.

\section{Case presentations}

A 57 year-old Caucasian male was admitted to the hospital because of severe left $\mathrm{L} 5$ radiculopathy. The pain in the left lower extremity started 2 months prior to admission and was associated with severe low back pain that resolved spontaneously within 3 weeks. The patient described the pain as dull, radiating to his left buttock, posterior thigh, antero-lateral shin and dorsum of his foot (Visual Analog Scale for the leg pain (VAS leg) of 7 out of 10 points). The pain was associated with muscle weakness on dorsal flexion of the left foot, paresthesia of the dorsal aspect of the left foot and tingling in the left big toe.

The patient was in good medical condition, wellnourished (Body Mass Index of $31.3 \mathrm{~kg} / \mathrm{m}^{2}$ ) and immunocompetent. He had a 10 year history of wellcontrolled blood hypertension and was allergic to bee stings. He denied any parasitic infections that he was aware of. He owned a dog that was living in the house and was regularly vaccinated and dewormed. No contact with wild animals was noted. Social history was remarkable for frequent travelling to Asia (Burma, Cambodia, Indonesia, Laos, Malaysia, Singapore, Thailand, Vietnam) and Africa (Nigeria) between 1994 and 2014 (during 21 years before the onset of the symptoms).

On physical examination the patient was alert and cooperative. His neurological examination was positive for muscle weakness on dorsal flexion of the left foot (4 out of 5 points according to Lovett's scale). The light touch and pin prick test were also impaired on the dorsal aspect of the left foot. Lasègue's sign was positive on 70 degrees flexion on the left side and negative on the right. No other abnormalities were detected.
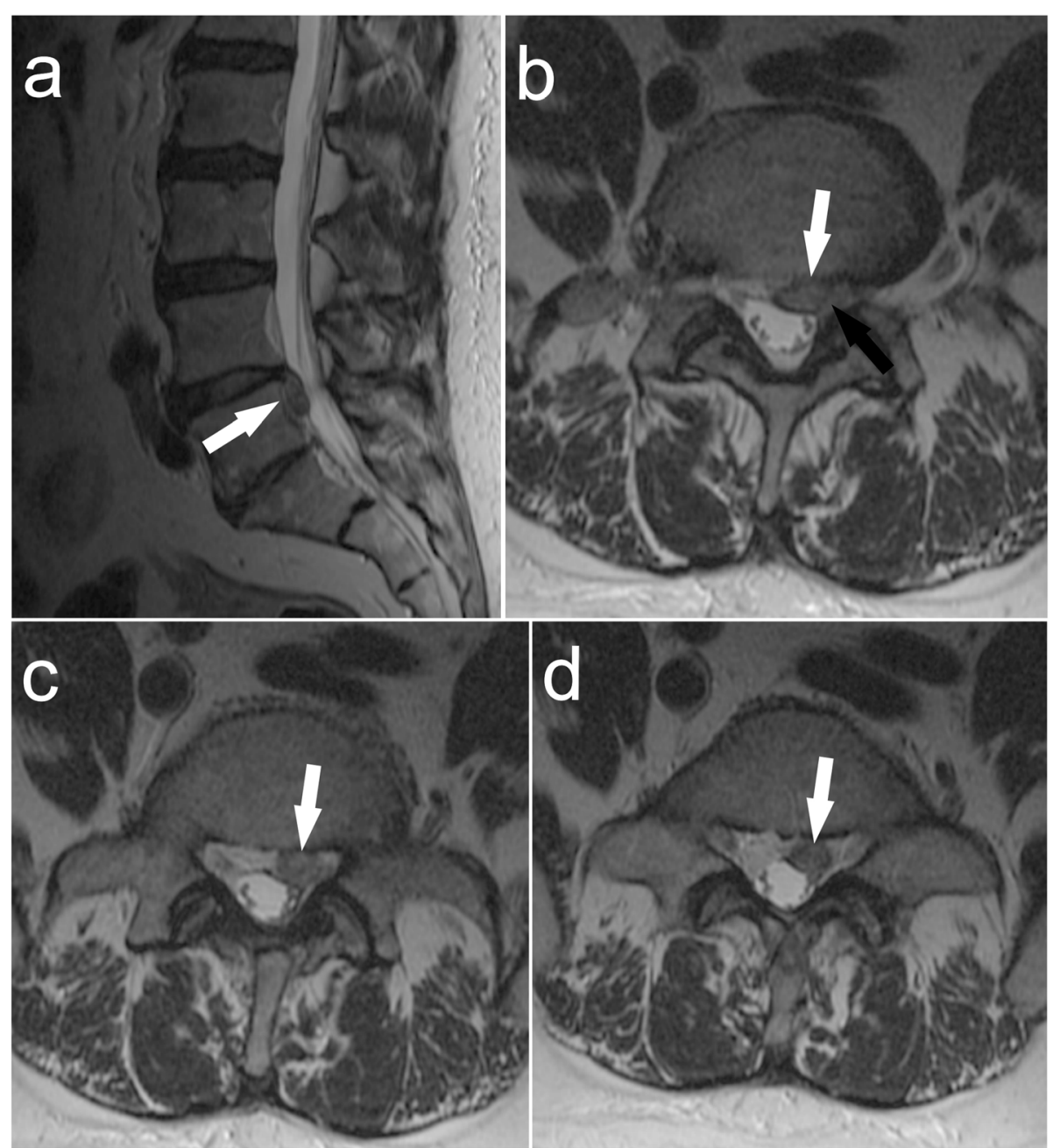

Fig. 1 Magnetic resonance imaging (MRI) presenting parasitosis of the spinal canal at L4-L5 level (white arrow) with compression of the left L5 nerve root (black arrow): $\mathbf{a}$ - sagittal view; b - axial view at L4-L5 level; c and $\mathbf{d}$ - axial view at L5 level 
Magnetic resonance imaging (MRI) examination of the lumbosacral spine revealed the L4-L5 intervertebral disc herniation with sequester compressing the left L5 nerve root within the left lateral recess of the spinal canal (Fig. 1). No abnormalities were found in the preoperative blood tests or urinalysis, with $\mathrm{WBC}$ count of $4,9 \mathrm{~K} / \mathrm{uL}$ erythrocyte sedimentation rate of $8 \mathrm{~mm} / \mathrm{h}$ and serum Creactive protein concentration of $0,5 \mathrm{mg} / \mathrm{L}$ ).

The patient was scheduled for an elective open left L4L5 discectomy. During the sequester evacuation the surgeon removed 3 pieces of nematodes (length about $22 \mathrm{~cm}, 20 \mathrm{~cm}$ and $15 \mathrm{~cm}$, respectively) that turned out to constitute the potential sequester compressing the L5 left nerve root (Fig. 2). The round worms were preserved in $10 \%$ formaldehyde and sent to the Department of Parasitology (Fig. 3). The preoperative, intraoperative and postoperative management was standard for an elective open discectomy, with antibiotic prophylaxis (2 $\mathrm{g}$ of Cefazolin iv $30 \mathrm{~min}$ before surgery) and irrigation with saline solution intraoperatively.

On postoperative day 1 the patient was pain free, besides a mild discomfort in the lumbar region. Lasègue's sign was negative on both sides. Sensation deficits or muscle weakness were not detected. Slight tingling in the left big toe was still present. In accordance with our post-discectomy protocol, patient ambulation was started on postoperative day 1 .

The following additional tests were performed: MRI with contrast (Gadolinium) of the head and cervical and thoracic spine as well as computed tomography $(\mathrm{CT})$ with contrast of the chest and abdomen, but revealed no other entities of parasitosis. Total serum immunoglobulin E concentration was within the normal values. No microfilaria or elevated eosinophil count was found in the blood smear.

The serological ELISA tests for toxocarosis and filariasis were negative. The diagnosis of dracunculiasis was based on the morphology of the nematode. DM infestation could not be confirmed with the molecular testing

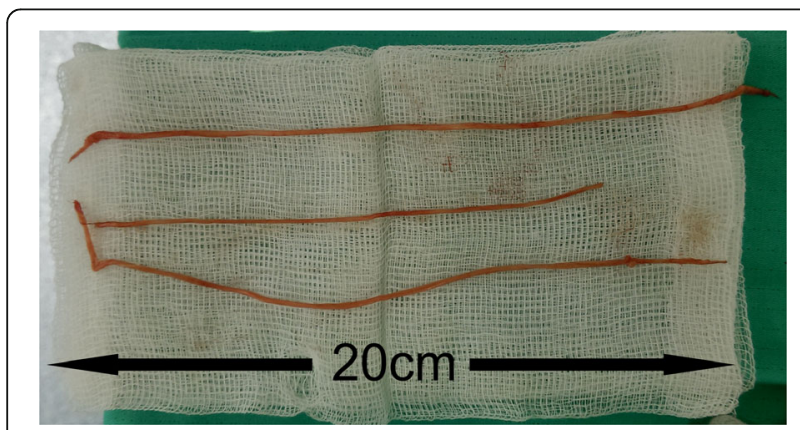

Fig. 2 Intraoperative picture of the nematode worm that was removed from the bulge located on the anterior wall of the spinal canal and compressing the left L5 nerve root

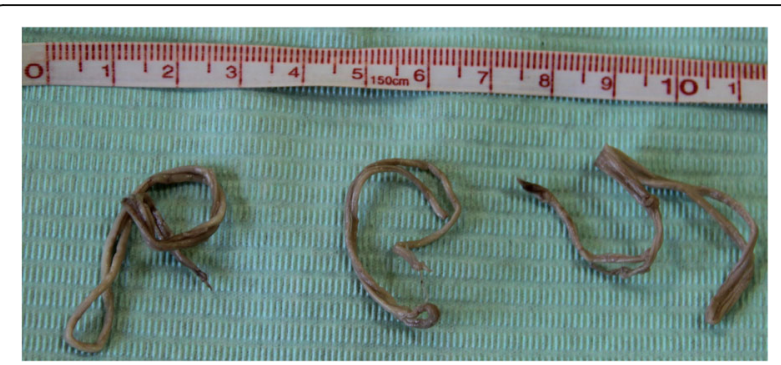

Fig. 3 The nematode worm after preservation in 10\% of formaldehyde solution

that was impaired by the formaldehyde used for preservation of the worm.

No other treatment for the patient was administered, according to the recommendations of the Department of Parasitology.

After 3 years the patient was admitted to the spine department again because of numbness of both lower extremities. The numbness started a few months prior to admission and was associated with mild intermittent low back pain. Apart from light touch impairment on the dorsal aspect of the left foot, no other abnormalities were detected on neurological examination.

The MRI examination revealed a degenerative disease of the lumbar spine with mild spinal canal stenosis on L3-L4 level. No sign of recurrence of dracunculiasis was observed. The patient was scheduled for an epidural steroid injection. After the procedure all symptoms resolved.

\section{Discussion and conclusions}

Parasitic infection of the spine is a rare condition. The most common parasites affecting the spinal canal include cysticercosis, schistosomiasis, toxoplasmosis and echinococcal disease, and are much more frequent in the developing countries of Asia and Africa [8]. The symptoms are caused by spinal cord compression or bone destruction of the vertebrae and are easy to confuse with other spine diseases such as tuberculosis, pyogenic infection, tumor or even intervertebral disc herniation. The diagnosis of spinal parasitosis is usually based on radiological findings and significant clinical history. Nowadays the gold standard for diagnosis of spinal parasitosis is MRI. Basing on radiological image one can differentiate various spinal parasitic infections. Neurocysticercosis can affect very diverse locations including the vertebrae, spinal cord, epidural, subdural or subarachnoid space, whereas neuroschistosomiasis usually forms an intramedullary granuloma. A typical manifestation of spinal cord toxoplasmosis is vacuolar myelopathy, with intramedullary ring-enhancing lesions. The last of the most common forms of spinal parasitosis, echinococcal disease, can cause cystic lesions in the 
vertebral bodies, bone lysis, spondylitis or spinal cord cysts [8].

This is the first report of dracunculiasis of the vertebral canal since the 1980s, when several cases were described [9-11] and the first ever described case where modern radiological imaging, such as computed tomography and magnetic resonance imaging, has been used.

Commonly, the first clinical manifestation of CNS dracunculiasis occurs 12 months after inoculation or skin manifestation. There are 3 types of neurological disorders caused by guinea worm: diffuse encephalopathy with intracerebral granulomas, intracranial hypertension due to blockage of CSF flow in the ventricular system by a granuloma and according to literature the least common, epiduritis, caused by adult worm migration [9]. The route of migration of dracunculus medinensis to the extradural space is probably from the retroperitoneal space through one of the intervertebral foramina [12].

Most of the previously reported cases were located in the epidural space of the cervical and upper thoracic spine, although the literature search revealed one case of lumbar spine infestation [9-12]. In this case the parasite caused extradural compression in the lumbar region with osteomyelitis of L5, that lead to a collapse of the vertebra. According to the authors an injured or lacerated guinea worm can cause a severe local inflammatory response [12].

Majority of patients presented symptoms of severe spinal canal stenosis including tetra- and paraparesis. Radiological findings include calcifications in the spinal canal at the level of compression on radiographs and complete or incomplete epidural block in myelography [9-11]. The laboratory tests were mostly negative, with a slightly elevated level of eosinophils in blood smear in some cases [11].

Intraoperatively, after a laminectomy and inspection of the vertebral canal, a granuloma with calcified nematode was usually found; however, in one case the surgeon evacuated from an epidural lesion a $60 \mathrm{~cm}$ long living parasite [10].

Literature does not describe an optimal surgical protocol for the treatment of dracunculiasis in unusual locations. The main treatment for common skin location is extraction of the parasite by gentle traction and winding around a stick, which can last from hours to months. The antihelminthic drugs such as niridazole, thiabendazole, or metronidazole can reduce the acute tissue reaction and help to extract the worm more easily [4].

Based on observations, two different types of evolution of spinal dracunculiasis have been distinguished:

- acute form - where neurological deficits develop in hours, and are preceded by $2-4$ months of back pain, with poor results of treatment
- subacute form - with months or weeks of back and radicular pain, with good results of treatment [11].

Although it is a rare condition, dracunculiasis should be taken into consideration even in cases with obvious lumbar intervertebral disc herniation seen on MRI, especially in patients travelling to the endemic areas. If a nematode is found accidentally during any surgery, it should be preserved in a $0.9 \%$ saline, not formaldehyde, to give valid results in molecular tests.

\section{Abbreviations \\ DM: Dracunculus medinensis; VAS: Visual Analog Scale; MRI: Magnetic resonance imaging; CT: Computed tomography; CNS: Central Nervous System; CSF: Cerebrospinal Fluid}

\section{Acknowledgements}

Not applicable.

\section{Authors' contributions}

MT study design, data collection, data interpretation, manuscript preparation, literature search. MK data collection, data interpretation, literature search. MCW data interpretation, manuscript preparation, literature search. JC data collection, data interpretation, manuscript preparation. All authors have read and approved the manuscript.

\section{Funding}

There was no financial support associated with preparation of this manuscript.

Availability of data and materials

All data generated or analysed during this study are included in this published article.

\section{Ethics approval and consent to participate}

The study was reviewed and approved by the Institutional Review Board of the Centre of Postgraduate Medical Education in Warsaw (Research Protocol \#90/PB/2015).

\section{Consent for publication}

Written informed consent was obtained from the patient for publication of this case report and any accompanying images. A copy of the written consent is available for review by the Editor-in-Chief of this journal.

\section{Competing interests}

Marcin Tyrakowski, Magdalena Kwiatkowska, Maria Czubak-Wrzosek, Jaroslaw Czubak declare that they have no conflict of interest.

\section{Author details}

${ }^{1}$ Department of Spine Disorders and Orthopedics, Centre of Postgraduate Medical Education in Warsaw, Konarskiego 13, 05-400 Otwock, Poland. ${ }^{2}$ Department of Orthopedics, Pediatric Orthopedics and Traumatology, Centre of Postgraduate Medical Education in Warsaw, Konarskiego 13, 05-400 Otwock, Poland

Received: 29 March 2020 Accepted: 10 December 2020 Published online: 05 January 2021

\section{References}

1. Biswas G, Sankara DP, Agua-Agum J, Maiga A. Dracunculiasis (Guinea worm disease): eradication without a drug or a vaccine. Philos Trans R Soc Lond Ser B Biol Sci. 2013;368(1623):20120146.

2. Greenaway C. Dracunculiasis (Guinea worm disease). CMAJ. 2004;170(4): 495-500.

3. Lupi O, Downing C, Lee M, Pino L, Bravo F, Giglio P, et al. Mucocutaneous manifestations of helminth infections: nematodes. J Am Acad Dermatol. 2015;73(6):929-44 quiz 45-6. 
4. Hesse AA, Nouri A, Hassan HS, Hashish AA. Parasitic infestations requiring surgical interventions. Semin Pediatr Surg. 2012;21(2):142-50.

5. Adoh A, Konin C, Adoubi A, Anzouan-Kacou JB, Niamkey T, Koffi J, et al. Unusual association of endomyocardial fibrosis and aberrant migration of Dracunculus medinensis in the pericardium. Bull Soc Pathol Exot. 2009; 102(2):88-90.

6. Gandhi VK, Maheshwari KL. Dracunculosis of radio-ulnar joint: an unusual manifestation. J Indian Med Assoc. 1991;89(11):314.

7. Drobis D. Dracontiasis as an unusual cause of Bartholin gland abscess. Ceska Gynekol. 1963;28:348-9.

8. Majmundar N, Patel PD, Dodson V, Tran A, Goldstein I, Assina R. Parasitic infections of the spine: case series and review of the literature. Neurosurg Focus. 2019;46(1):E12.

9. Legmann P, Chiras J, Launay M, Philippon J, Bories J. Epidural dracunculiasis: a rare cause of spinal cord compression. Neuroradiology. 1980;20(1):43-5.

10. Chapard C, Roux FX, George B, Rey A, Kafiluddin K. Intraspinal dracunculosis. Apropos of a case of epidural medullary compression. Neurochirurgie. 1982; 28(5):339-42.

11. Marion MH, Rivierez M, Chiraz J, Porta M. Compression medulaire par filaire de medine un nouveau cas. Revue De Medecine. 1983;24(20):901-4.

12. Mathur PP, Dharker SR, Hiran S, Sardana V. Lumbar extradural compression by guinea worm infestation. Surg Neurol. 1982;17(2):127-9.

\section{Publisher's Note}

Springer Nature remains neutral with regard to jurisdictional claims in published maps and institutional affiliations.

Ready to submit your research? Choose BMC and benefit from:

- fast, convenient online submission

- thorough peer review by experienced researchers in your field

- rapid publication on acceptance

- support for research data, including large and complex data types

- gold Open Access which fosters wider collaboration and increased citations

- maximum visibility for your research: over $100 \mathrm{M}$ website views per year

At BMC, research is always in progress.

Learn more biomedcentral.com/submissions 